\title{
Autologous Whole Blood Injection For COVID-19 Can Reduce Cytokine Storm and Severity of IIIness
}

\author{
M. Christopher ${ }^{1 *}$, C. Jerriton Brewin ${ }^{2}$, Ramesh Babu ${ }^{3}$, M. Mohamed Arafath ${ }^{4}$, J. Auspas ${ }^{5}$, 5 R \\ Tiruvalavan $^{6}$
}

DOI: https://doi.org/10.17511/ijmrr.2021.i03.02

1* M. Christopher, Consultant Anesthetist, , Shifa Hospitals, Tirunelveli, Tamil Nadu, India.

${ }^{2}$ C. Jerriton Brewin, Final year Post Graduate in M.D (DVL), Sri Venkateshwaraa Medical College Hospital and Research Centre, Pondicherry, India.

3 Ramesh Babu, Head of Department of Microbiology, Panimalar Medical College, Chennai, Tamil Nadu, India.

4 M. Mohamed Arafath, M.D (General Medicine), Medical Director, Shifa Hospital, Tirunelveli, Tamil Nadu, India.

5 J. Auspas, Assistant Professor, Department of General Medicine, Coimbatore Medical College, Coimbatore, Tamil Nadu, India.

6 S R Tiruvalavan, M.D. (Pharmacology)., M.B.A Lead Clinical Research, Shanmuga Hospital, Salem, Tamil Nadu, India.

Autologous whole blood injection is used for various indications. It has an immunomodulatory action on the immune system. A randomized controlled two-arm study was conducted to determine IL- 6 levels, CT changes and mortality among adult COVID-19 patients. The trial included 30 patients divided into two groups. The interventional group received 2 doses of $2.5 \mathrm{ml}$ of autologous whole blood injection spaced 2 days apart. There was a statistically significant reduction in IL-6 levels on day 6 in the group receiving treatment. CT score improved in patients who received treatment. No cases of mortality were reported in the treatment group. Autologous whole blood injection can be used as a simple, low-cost adjuvant in the treatment of adult COVID-19 patients, regardless of disease severity.

Keywords: Autologous whole blood, Autohemotherapy, Covid19 treatment

Corresponding Author

M. Christopher, Consultant Anesthetist, Shifa Hospitals, Tirunelveli, Tamil Nadu, India.

Email: dr.chris.judith@gmail.com
How to Cite this Article

To Browse

M Christopher, C Jerriton Brewin, Ramesh Babu, M Mohamed Arafath, J Auspas, S R Tiruvalavan. Autologous Whole Blood Injection For COVID-19 Can Reduce Cytokine Storm and Severity of Illness. Int J Med Res Rev. 2021;9(3):141-145.

Available From

https://ijmrr.medresearch.in/index.php/ijmrr/article/

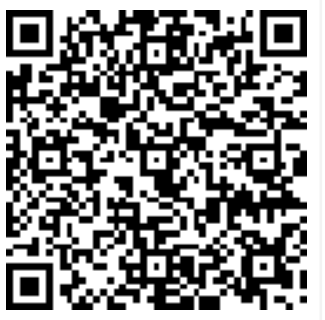
view/1289

Manuscript Received 2021-05-07

Conflict of Interest No
Review Round 1 2021-05-17

Funding Yes
Review Round 2 2021-05-25

Ethical Approval Yes
Review Round 3

Plagiarism X-checker $9 \%$
Accepted 2021-06-03

Note

(C) 2021 by M. Christopher, C. Jerriton Brewin, Ramesh Babu, M. Mohamed Arafath, J. Auspas, S R Tiruvalavan and Published by Siddharth Health Research and Social Welfare Society. This is an Open Access article licensed under a Creative Commons Attribution 4.0 International License https://creativecommons.org/licenses/by/4.0/ unported [CC BY 4.0] 


\section{Introduction}

Coronavirus disease 2019 (COVID-19) is caused by severe acute respiratory syndrome-coronavirus 2 (SARS-CoV-2) and has become a global pandemic of the highest concern. The severity of COVID-19 has been measured by several parameters such as organ dysfunction, biochemical parameters, radiological findings, duration of intervention, quality of life, viral burden, survival, clinical progression and others [1]. The main cause of death is acute respiratory distress syndrome with the cytokine storm [2]. The release of proinflammatory cytokines such as interleukin-6 (IL-6) might play a key role in the pathophysiology of COVID-19. [3]. IL-6 level is increased in the cytokine storm and it promotes a Th2 differentiation, leading to respiratory failure and death in COVID-19 patients $[4,5]$.

Current treatments for COVID-19 are limited either by their side effects or their affordability and availability. Autologous whole blood (AWB) injection is a simple, low-cost and easily accessible treatment with minimum side effects. It has been used as a treatment for various indications including chronic urticaria, atopic dermatitis, herpes virus infections, epicondylitis, post-operative ocular hypotony and others $[6,7]$. It has an immunomodulatory action that can skew the Th2 cytokine pattern to Th1, leading to a better prognosis in COVID-19 patients by reducing the cytokine storm $[6,8]$. It can also act as a vaccine as the antigens present in the whole blood are processed and presented to the immune system by the dendritic cells of the muscle, generating an antigen-specific response in the body $[9,10]$. This is the first study to use unprocessed AWB injection in the treatment of COVID-19 infection.

\section{Methods}

An open label, two-arm, parallel, randomized control, small scale preliminary study was conducted to determine the severity outcomes in terms of CT chest severity score, IL-6 levels and mortality among adult COVID-19 patients of mild, moderate and severe disease. The trial was approved by Shifa Hospital - Institutional Ethics Committee (ECR/1244/Inst/TN/2019) and registered with the Clinical Trial Registry of India (CTRI/2020/09/027904). Written informed consent was obtained from all patients.
The trial included 30 patients admitted to Shifa Hospital, Tirunelveli, Tamil Nadu, India. The duration of the study was 6 months between October 2020 and March 2021. Inclusion criteria: Reverse Transcription PCR (RT-PCR) confirmed cases of clinically suspected cases with CT chest features consistent with COVID-19 aged 18 years old and older, regardless of disease severity. Exclusion criteria: Patients on anti-platelets or anticoagulants, bleeding disorders, chronic illnesses (e.g., ischemic heart disease, heart failure, cardiomyopathy, chronic renal disease, chronic liver disease) and pregnant and lactating women were excluded from the study. A detailed history and clinical examination were done and documented in a pre-structured proforma. CT chest was done on enrollment day, day 7 and 14. Quantitative serum IL-6 levels were done on enrollment day, day 3, 6, 9 and 12. All patients were followed up for 2 months for mortality. Randomization: Patients were randomized in a 1:1 manner as per a computerized generated sequence on admission and they were assigned to one of two groups: group A receiving standard COVID treatment plus intramuscular AWB injections and group $B$ receiving standard COVID treatment alone.

Intervention: Participants in group B (control arm) received standard COVID treatment as per the institution's protocol. Participants in group A (interventional arm) received standard treatments and observations as per the control group and in addition received intramuscular (intragluteal) injection of $2.5 \mathrm{ml}$ of their own unmodified venous whole blood using a $22 \mathrm{G}$ needle and a $5 \mathrm{ml}$ syringe. The freshly drawn venous blood was administered within a minute into the gluteal muscle of the same individual on enrollment day and day 3 . The injections were administered by nursing staff under the direct observation of the principal investigator. Side effects of the intervention were recorded.

Outcomes: Primary outcomes were assessed for CT chest severity score, IL-6 levels and mortality. Categorization into normal, mild, moderate and severe was done for CT score and IL- 6 levels based on their scores and levels, respectively. Participants with CT score less than or equal to $8 / 25$ were categorized as mild scores. Those with CT score 9$15 / 25$ were categorized as moderate score and those above $15 / 25$ were categorized as severe score. An IL-6 level less than $7 \mathrm{pg} / \mathrm{ml}$ was considered normal. A value of $8-15 \mathrm{pg} / \mathrm{ml}$ was categorized as mild rise. 
Those with level $15-100 \mathrm{pg} / \mathrm{ml}$ were categorized as moderate rise and those above $100 \mathrm{pg} / \mathrm{ml}$ were categorized as a severe rise in IL-6 levels. Sample size calculation: The exploratory trial design did not mandate sample size calculation for efficacy. Being a new intervention, ethical clearance was granted for 30 patients.

Statistical analysis: Data was entered into SPSS software (version 17.0). Baseline categorical and continuous variables were compared between the groups using Fisher's exact test and unpaired t-test, respectively. A Chi-square test was done to determine the significance of changes in CT score and IL- 6 levels and a p-value of $<0.05$ was taken as a statistically significant difference.

\section{Results}

A total of 30 patients were enrolled in the trial; 15 patients were included per study arm. The demographics, history, co-morbidities and pretreatment disease severity were comparable among both groups. The mean age was $59.8 \pm 12.04$ years (mean \pm SD) and $63.33 \%$ were males. The duration of illness before the assessment was an average of 4.63 days.
Improvement from moderate to mild CT score was seen in $2(13.33 \%)$ patients on day 7 in the interventional arm. In group B (control arm), 3 $(11.11 \%)$ patients deteriorated from moderate to severe CT score on day 7. But the differences were not statistically significant $(p=0.065)$ (Table 1 ). Improvement in IL-6 levels (severe to moderate in $6.67 \%$, moderate to mild in $13.33 \%$, moderate to normal in $6.67 \%$ and mild to normal in $26.67 \%$ ) was seen in $8(53.33 \%)$ patients on day 6 in the interventional arm. Deterioration in IL-6 levels (normal to mild in 20\%, normal to moderate in $6.67 \%$ and mild to moderate in $20 \%$ ) was seen in 7 $(58.33 \%)$ patients on day 6 in the control arm. The differences were statistically significant $(p=0.001)$ (Table 2).

There were 3 in-hospital deaths in group B within 5 days of admission whereas all patients in group $A$ who received AWB injections survived. All 3 patients who died in group $B$ had mild to moderate disease with high IL-6 levels on admission. No side effects of AWB injection were noted apart from minimal pain on injection.

Table-1: Comparison of CT changes on day 7 in both groups

\begin{tabular}{|c|c|c|c|c|c|c|c|}
\hline & & & & & & \multirow[t]{2}{*}{ Total } & \multirow[t]{2}{*}{ P-value } \\
\hline & & & No changes & Improved & Deteriorate & & \\
\hline \multirow[t]{4}{*}{ Group } & \multirow[t]{2}{*}{ Group A } & Count & 13 & 2 & 0 & 15 & \multirow[t]{6}{*}{0.065} \\
\hline & & $\%$ within Group & $86.7 \%$ & $13.3 \%$ & $0.0 \%$ & $100.0 \%$ & \\
\hline & \multirow[t]{2}{*}{ Group B } & Count & 9 & 0 & 3 & 12 & \\
\hline & & $\%$ within Group & $75.0 \%$ & $0.0 \%$ & $25.0 \%$ & $100.0 \%$ & \\
\hline \multirow[t]{2}{*}{ Total } & & Count & 22 & 2 & 3 & 27 & \\
\hline & & $\%$ within Group & $81.5 \%$ & $7.4 \%$ & $11.1 \%$ & $100.0 \%$ & \\
\hline
\end{tabular}

Table-2: Comparison of changes in IL- 6 levels on day 6 in both groups

\begin{tabular}{|c|c|c|c|c|c|c|c|}
\hline & & & & & & \multirow{2}{*}{$\overline{\text { Total }}$} & \multirow{2}{*}{$P$ value } \\
\hline & & & No changes & Improved & Deteriorated & & \\
\hline \multirow[t]{4}{*}{ Group } & \multirow[t]{2}{*}{ Group A } & Count & 7 & 8 & 0 & 15 & \multirow[t]{6}{*}{0.001} \\
\hline & & $\%$ within Group & $46.7 \%$ & $53.3 \%$ & $0.0 \%$ & $100.0 \%$ & \\
\hline & \multirow[t]{2}{*}{ Group B } & Count & 5 & 0 & 7 & 12 & \\
\hline & & $\%$ within Group & $41.7 \%$ & $0.0 \%$ & $58.3 \%$ & $100.0 \%$ & \\
\hline \multirow{2}{*}{\multicolumn{2}{|c|}{ Total }} & Count & 12 & 8 & 7 & 27 & \\
\hline & & $\%$ within Group & $44.4 \%$ & $29.6 \%$ & $25.9 \%$ & $100.0 \%$ & \\
\hline
\end{tabular}

\section{Discussion}

Autologous blood therapy finds its application in both complementary medicine and general medical use for many years.
There are different methods of applying autologous blood: intravenous injection, intramuscular injection and local injection at diseased sites.[6] In a study by John $\mathrm{H}$. Olwin et al [7], unmodified autologous whole blood was successfully used in treating 
22 patients with herpes zoster viral infection and 3 patients with herpes simplex viral infection. They suggest the possibility of immunomodulation resulting in increased interferons (IFN) $a$ and $Y$ and interleukin-4 as an effector mechanism of AWB injection. Unmodified AWB has also been used successfully in treating chronic urticaria. The proposed mechanism is immunomodulation resulting in immune tolerance and desensitization to histamine-releasing factors.[10]

Another proposed immunomodulatory action in chronic urticaria includes a reduction in Th2 cytokines and promotion of Th1 cytokines.[6] Since SARS-CoV-2 can suppress IFN signalling and impair viral clearance [11], AWB injection may increase IFN levels required for viral clearance. AWB injection may also reduce Th2 cytokine levels resulting in reduced inflammation in COVID-19. When introduced into the gluteal muscle, the viral antigens contained in the whole blood may also desensitize the individual and thereby reduce the hyperinflammatory response to the viral antigens.

Our study showed that two doses of $2.5 \mathrm{ml}$ of AWB injections spaced two days apart significantly reduced the levels of IL- 6 on day 6 in COVID-19 patients, regardless of pre-treatment disease severity. There was also improvement in CT severity scores on day 7 in the interventional arm. To the best of our knowledge, no studies have been done with unmodified AWB for treating COVID-19. It is cheap, requiring only a disposable syringe and needle and easy to administer by any healthcare worker.

It is readily available and time-tested to be extremely safe. It is thus a highly attractive adjuvant for the treatment of all COVID-19 patients. AWB injection as a vaccine for prophylaxis against COVID-19 infection is an interesting proposal to be explored. A large-scale study is required to confirm the validity of the results.

Funding source: This work was supported by Mr. Gunasingh Chelladurai, Bell Foundation, Tirunelveli, Tamil Nadu, India.

Ethical review: The trial was approved by the Shifa Hospital - Institutional Ethics Committee (ECR/1244/Inst/TN/2019) and registered with the Clinical Trial Registry of India (CTRI/2020/09/027904). Written and informed consent was obtained from all patients.
Declaration of interests: The authors declare that there are no known competing financial interests or personal relationships that could have appeared to influence the work described in this paper.

Acknowledgement: Nil.

Conflicts of interest: The authors have no conflicts of interest to declare.

\section{Reference}

01. WHO Working Group on the Clinical Characterisation and Management of COVID-19 infection. A minimal common outcome measure set for COVID-19 clinical research. Lancet Infect Dis. 2020 Aug;20(8)e192-e197. doi: 10.1016/S14733099(20)30483-7 [Crossref][PubMed][Google Scholar]

02. Hojyo S, Uchida M, Tanaka K, Hasebe R, Tanaka $Y$, Murakami $M$, et al. How COVID-19 induces cytokine storm with high mortality. Inflamm Regen. 2020 Oct 1;40;37. doi: 10.1186/s41232-02000146-3 [Crossref][PubMed][Google Scholar]

03. Gupta S, Leaf DE. Tocilizumab in COVID-19some clarity amid controversy. Lancet. 2021 May 1;397(10285)1599-1601. doi: 10.1016/S01406736(21)00712-1 [Crossref][PubMed][Google Scholar]

04. Chen LYC, Hoiland RL, Stukas S, Wellington CL, Sekhon MS. Confronting the controversyinterleukin-6 and the COVID-19 cytokine storm syndrome. Eur Respir J. 2020 Oct 1;56(4)2003006. doi: 10.1183/13993003.03006-2020 [Crossref] [PubMed][Google Scholar]

05. Diehl S, Rincón M. The two faces of IL-6 on Th1/Th2 differentiation. Mol Immunol. 2002 Dec;39(9)531-6. doi: 10.1016/s0161-5890(02) 00210-9 [Crossref][PubMed][Google Scholar]

06. Oomen-Welke K, Huber R. Intramuscular autologous blood therapy- a systematic review of controlled trials. BMC Complement Altern Med. 2019 Sep 5;19(1)248. doi: 10.1186/s12906-019-2643-0 [Crossref][PubMed][Google Scholar]

07. Olwin JH, Ratajczak HV, House RV. Successful treatment of herpetic infections by autohemotherapy. J Altern Complement Med. 1997 Summer;3(2)155-8. doi: 10.1089/acm.1997.3.155 [Crossref][PubMed][Google Scholar] 
08. Gil-Etayo FJ, Suàrez-Fernández $P$, CabreraMarante O, Arroyo D, Garcinuño S, Naranjo L, et al. T-Helper Cell Subset Response Is a Determining Factor in COVID-19 Progression. Front Cell Infect Microbiol. 2021 Feb 26;11;624483. doi: 10.3389/fcimb.2021.624483 [Crossref][PubMed] [Google Scholar]

09. Hakimi J, Azizi A, Ausar SF, Todryk SM, Rahman $\mathrm{N}$, Brookes $\mathrm{RH}$. An adjuvant-modulated vaccine response in human whole blood. Hum Vaccin Immunother. 2017 Sep 2;13(9)2130-2134. doi: 10.1080/21645515.2017.1337616 [Crossref] [PubMed][Google Scholar]
10. Sheikhi A, Azarbeig $M$, Karimi $H$. Autohemotherapy in chronic urticaria- what could be the autoreactive factors and curative mechanisms?. Ann Dermatol. 2014 Aug;26(4)526-7. doi: 10.5021/ad.2014.26.4.526 [Crossref][PubMed] [Google Scholar]

11. Gustine JN, Jones D. Immunopathology of Hyperinflammation in COVID-19. Am J Pathol. 2021 Jan;191(1)4-17. doi: 10.1016/j.ajpath.2020.08.009 [Crossref][PubMed][Google Scholar] 